\title{
TWIST1 GENE EXPRESSION AS A BIOMARKER FOR PREDICTING PRIMARY DOXORUBICIN RESISTANCE IN BREAST CANCER
}

\author{
Demir $\mathrm{S}^{1,10, *}$, Müslümanoğlu $\mathrm{MH}^{2}$, Müslümanoğlu $\mathrm{M}^{3}$, Başaran $\mathrm{S}^{4}$, \\ Çalay ZZ ${ }^{5}$, Aydıner A ${ }^{6}$, Vogt U ${ }^{7}$, Çakır T ${ }^{8}$, Kadığ lu $\mathrm{H}^{9}$, Artan $\mathrm{S}^{1}$ \\ *Corresponding Author: Selma Demir, Ph.D., Trakya University Faculty of Medicine, Department of \\ Medical Genetics, 22030 Iskender, Edirne, Turkey. Tel: +90(284)2357642/2330. Fax: +90(284)2357652. \\ E-mail: selmaulusal@trakya.edu.tr
}

\begin{abstract}
Doxorubicin is one of the most commonly used chemotherapeutic agents for adjuvant chemotherapy of breast cancer. In the studies focused on finding biomarkers to predict the response of the patients and tumors to the drugs used, the Twist transcription factor has been suggested as a candidate biomarker for predicting chemo-resistance of breast tumors. In this study, we aimed to investigate the relationship between TWIST transcription factor expression and the effectiveness of doxorubicin treatment on directly taken primary tumor samples from chemotherapy-naive breast cancer patients. Twenty-six primary breast tumor samples taken from 26 different breast cancer patients were included in this study. Adenosine triphosphate tumor chemo-sensitivity assay (ATP-TCA) has been used to determine tumor response to doxorubicin and real-time
\end{abstract}

\footnotetext{
${ }^{1}$ Eskişehir Osmangazi University Faculty of Medicine Department of Medical Genetics, Eskişehir, Turkey

${ }^{2}$ Y 1 ldı Technical University Faculty of Science and Literature Department of Molecular Biology and Genetics, Istanbul, Turkey

${ }^{3}$ Bezmialem University Faculty of Medicine Department of General Surgery, Istanbul, Turkey

${ }^{4}$ Istanbul University Faculty of Medicine Department of Medical Genetics, Istanbul, Turkey

${ }^{5}$ Istanbul University Cerrahpaşa Medical Faculty Department of Pathology, Istanbul, Turkey

${ }^{6}$ Istanbul University Faculty of Medicine Department of Medical Oncology, Istanbul, Turkey

${ }^{7}$ European Laboratory Association ELA, Ibbenbueren, Germany

${ }^{8}$ Gebze Technical University Faculty of Engineering Department of Bioengineering, Istanbul, Turkey

${ }^{9}$ Medicana Hospital, Department of General Surgery, Bahçelievler, İstanbul

${ }^{10}$ Trakya University, Faculty of Medicine, Department of Medical Genetics, Edirne, Turkey
}

reverse-transcription polymerase chain reaction (RT-PCR) was used for analyzing the TWIST1 gene expression of tumors. There was a significant difference in TWIST gene expression between responder and non responder tumors ( $p$ $<0.05$ ). The TWIST gene expression of the drug-resistant group was higher than the responsive group. This difference was not dependent on the histopathological features of tumors. In conclusion, compatible with earlier studies that have been performed with cell lines, the current study supports the role of higher TWIST gene expression as a biomarker for predicting the response of breast tumors to chemo-therapeutic agent doxorubicin.

Keywords: Biomarker; Breast cancer; Chemotherapy; Expression; TWIST1 gene.

\section{INTRODUCTION}

Breast cancer is the most common cancer in women and is also responsible for a great number of cancer-associated deaths among women worldwide $[1,2]$. Several chemo-therapeutic agents, either alone or in addition to other therapies, are used in the treatment of breast cancer patients. Anthracyclines and taxanes are the most commonly used chemo-therapeutics for breast cancer treatment [3]. Benefit and risk assessment for therapeutic agents for each patient is important because chemotherapy is a conventional method targeting all fast-dividing cells of the organism [4]. Toxicity and primary or secondary resistance are common problems of conventional chemotherapy. Thus, studies focusing on finding biomarkers to predict the response of the patients and tumors to the drugs used are an important part of precision medicine [5].

The twist transcription factor, encoded by the TWIST1 gene (TWIST1; OMIM* 601622) is a member of the basic helix loop helix transcription factor family and has an 
important role in cell lineage determination and differentiation as an essential regulator during embryogenesis, particularly in mesoderm formation, specification, and differentiation. Pathogenic variations of the TWIST1 gene leads to Saethre-Chotzen syndrome (\#101400), Craniosynostosis 1 (\#123100), Robinow-Sorauf syndrome (\#180750) and Sweeney-Cox syndrome (\#617746) in humans [6]. Some studies have extensively demonstrated that the twist transcription is implicated initiation [7], stemness [8], angiogenesis [9] and chemo-resistance in some types of carcinomas, sarcomas and hematological malignancies $[10,11]$. Induced twist overexpression has been shown to be related to chemo-resistance of breast tumor cells in a study performed on breast tumor cell lines [10]. Twist overexpression has been shown to be related to clinicopathological features of tumors and reported to be a candidate biomarker of shorter overall survival [12].

In this study, we aimed to investigate the relationship between intrinsic TWIST transcription factor expression and the effectiveness of doxorubicin treatment on primary tumor samples directly taken from different chemotherapynaive breast cancer patients. As far as we know, there are no studies investigating the association of the TWIST gene expression differences in primary breast tumor samples taken from patients and their primary sensitivity to doxorubicin.

\section{MATERIALS AND METHODS}

Sample Collection. Twenty-six primary breast tumor samples taken from 26 different untreated breast cancer patients (26 women, mean age: 53.4 ) following permission of the institutional ethics board, were included in this study. Samples were taken from the breast tumors during initial breast surgery. Tumor cell content of collected samples was confirmed by imprint cytology. Samples were cut into two pieces of about $0.5 \mathrm{~cm}^{3}$. One piece of each tumor sample was put into an RNA stabilization reagent (RNAlater; Qiagen $\mathrm{GmbH}$, Hilden, Germany) for protection of the RNA content until RNA isolation, and the other half was put directly into the $0.2 \%$ antimycotic/antibacterial added $7 \mathrm{~mL}$ transport medium [Dulbecco's modified eagle medium (DMEM)], for transportation to the laboratory for adenosine triphosphate tumor chemo-sensitivity assay (ATP-TCA).

Adenosine Triphosphate Tumor Chemo-Sensitivity Assay. A modified cell viability method of Andreotti et al. [13] was used to determine the responses of tumor cells to doxorubicin. Breast cancer tissue samples were mechanistically fragmented and treated for 12 hours with $10 \mathrm{~mL}$ sterile tumor dissociation enzyme reagent (TDR) in the incubator $\left(37^{\circ} \mathrm{C}, 5.0 \% \mathrm{CO}_{2}\right)$ before resuspension $(1.5 \times$ 105 cells $/ \mathrm{mL}$ ) in DMEM (Gibco Thermo Fisher Scientific,
Waltham, MA, USA). Therapeutic drug preparations from commercial sources were stored and used before expiration dates according to the manufacturer's instructions. Doxorubicin was prepared in six dilutions corresponding to $200.0,100.0,50.0,25.0,12.5$ and $6.25 \%$, respectively, of each standard test drug concentration (TDC). One hundred percent TDC value used for doxorubicin was $0.5 \mathrm{~g} /$ $\mathrm{mL}$ [13-15]. Cultures of approximately 15,000-20,000 cells/ well were tested in 96-well microplates (Costar; Merck KGaA, Darmstadt, Germany) containing both 12 maximum inhibition control wells (i.e., negative controls containing no cells) and 12 no inhibition control wells. Cultures were incubated for 8 days at $37{ }^{\circ} \mathrm{C}$ in a $>98.0 \%$ humidified, $95.0 \%$ air and $5.0 \% \mathrm{CO}_{2}$ atmosphere; then cellular adenosine triphosphate (ATP) was extracted and stabilized by mixing cell lysing reagent (Merck KGaA) into each well. The ATP was measured in a BMG LUMIstar (BMG Labtech GmbH, Ortenberg, Germany) using the 1:1 mix containing cell lysate and Luciferin-Luciferase counting reagent (Merck KGaA). A 5 second-count integration with a 1 second delay was used. Each measurement was performed three times. After incubation for 6 days with the drug, percentages of breast tumor cell growth inhibition (BTGI) compared with control cultures was determined. The area under the curve (AUC) values were calculated using the trapezoidal rule [16].

RNA Isolation and Real-Time RT-PCR. Fresh tissue samples kept in RNAlater solution was lysed and homogenized using Tissue Lyser LT followed by manual RNA isolation performed with RNeasy Mini Kit (Qiagen $\mathrm{GmbH}$ ) according to the manufacturer's instructions. The RNA concentration was measured using the NanoDrop 1000 spectrophotometer (Thermo Fisher Scientific) using the Transcriptor First Strand cDNA Synthesis Kit (Roche Diagnostics, Mannheim, Germany), 150 ng of total RNA was reverse transcribed with the combination of anchoredoligo(dT) and random hexamer primers included in the kit. TWIST gene expression of tumor samples was determined by real-time reverse-transcription polymerase chain reaction (RT-PCR) using $\beta$-actin gene expression as the reference ( Real-Time Ready Gene Expression Assay; Roche Diagnostics). All reactions were duplicated on a LightCycler ${ }^{\circledR} 480$ (Roche Diagnostics). Gene expression differences of tumor samples were determined using the $\Delta \Delta \mathrm{CT}\left(2^{-\Delta \Delta \mathrm{CT}}\right)$ method [17]. The Statistical Package for the Social Sciences (SPSS $®$ ) version 11 (https://www. ibm.com) was used to determine the relationship between TWIST gene expression status and other tumor parameters and in vitro chemo-response of tumors to doxorubicin. The Mann-Whitney U test in the SPSS program has been used to determine if gene expression differences are related to chemo-response of tumors. 


\section{RESULTS}

ATP-TCA Results. Nine out of 26 tumors were found to be resistant to doxorubicin. Histological grade, HER2, estrogen and progesterone receptor positivity and lymph node metastasis status of responsive and non responsive tumors did not differ significantly. Findings and clinical characteristics of the responsive and non responsive tumor samples are summarized in Table 1.

TWIST1 Gene Expression Results. When tumors were grouped according to their response to the chemotherapeutic agent doxorubicin, there was a significant difference for TWIST gene expression between responders and non responders $(p=0.041)$ (Figure1). TWIST gene expression of the drug-resistant group was higher than the responsive group. This difference was not dependent on the histopathological features of tumors because the TWIST gene expression difference was not significantly differed according to histological grade, hormone receptor or lymph node positivity and HER2 (erb-b2 receptor tyrosine kinase 2) status. The results are summarized in Table 1.

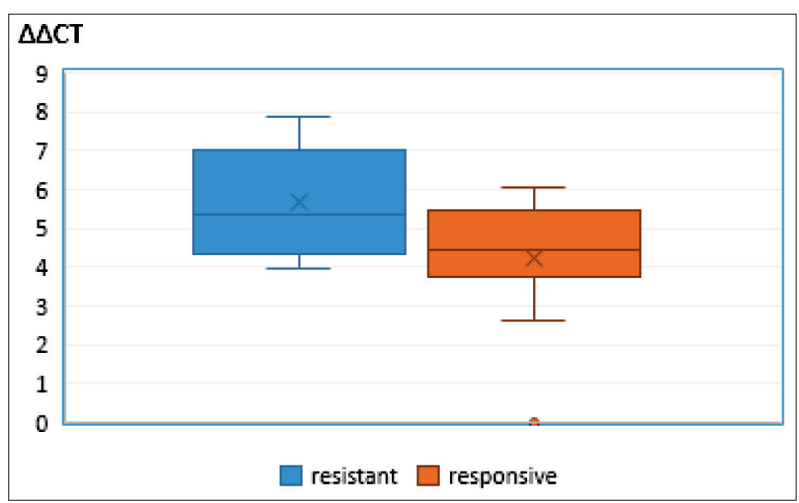

Figure 1. The $2^{-\triangle \Delta C T}$ differences of resistant and responsive tumor groups $(\mathrm{p}=0,041)$.

Table 1. Clinopathological characteristics, TWIST gene expression results and ATP-TCA results of samples.

\begin{tabular}{|c|c|c|c|c|c|c|c|}
\hline Sample & $\begin{array}{l}\text { Tumor } \\
\text { Grade }\end{array}$ & ER & PR & HER2 & Diagnosis & $\begin{array}{l}\text { TWIST1 Gene } \\
\text { Expression } \\
\text { Fold-Change }\end{array}$ & $\begin{array}{c}\text { ATP-TCA } \\
\text { Results }\end{array}$ \\
\hline S1 & 3 & {$[+]$} & {$[+]$} & {$[-]$} & IDC & 4.25 & NR \\
\hline S2 & 2 & {$[+]$} & {$[+]$} & {$[-]$} & IDC & 7.85 & NR \\
\hline S3 & 3 & {$[+]$} & {$[+]$} & {$[-]$} & IDC & 6.70 & NR \\
\hline S5 & 3 & {$[+]$} & {$[-]$} & {$[-]$} & IDC & 4.26 & $\mathrm{R}$ \\
\hline S6 & 3 & {$[+]$} & {$[+]$} & {$[+]$} & IDC & 5.80 & $\mathrm{R}$ \\
\hline S7 & 3 & {$[+]$} & {$[+]$} & {$[-]$} & IDC; multifocal & 5.36 & $\mathrm{R}$ \\
\hline S9 & 3 & {$[+]$} & {$[+]$} & {$[-]$} & IDC & 4.74 & $\mathrm{R}$ \\
\hline S10 & 3 & {$[+]$} & {$[+]$} & {$[+]$} & IDC & 3.67 & $\mathrm{R}$ \\
\hline S11 & 3 & {$[+]$} & {$[+]$} & {$[+]$} & IDC & 6.06 & $\mathrm{R}$ \\
\hline S12 & 3 & {$[+]$} & {$[-]$} & {$[+]$} & IDC & 4.44 & $\mathrm{R}$ \\
\hline S13 & 3 & {$[+]$} & {$[+]$} & {$[+]$} & mixed IDC and IDC-L & 5.84 & NR \\
\hline S14 & 3 & {$[+]$} & {$[+]$} & {$[+]$} & IDC; multifocal & 4.51 & $\mathrm{R}$ \\
\hline S15 & 2 & {$[+]$} & {$[+]$} & {$[-]$} & mixed IDC and IDC-L & 3.87 & $\mathrm{R}$ \\
\hline S17 & 3 & {$[+]$} & {$[+]$} & {$[-]$} & IDC & 4.88 & $\mathrm{R}$ \\
\hline S18 & 3 & {$[-]$} & {$[-]$} & {$[-]$} & IDC & 5.56 & $\mathrm{R}$ \\
\hline S19 & 2 & {$[+]$} & {$[+]$} & {$[-]$} & IDC & 5.56 & $\mathrm{R}$ \\
\hline S21 & 2 & {$[+]$} & {$[+]$} & {$[+]$} & mixed IDC and IDC-L; multifocal & 5.28 & NR \\
\hline S22 & 2 & {$[+]$} & {$[+]$} & {$[-]$} & IDC & 4.18 & $\mathrm{R}$ \\
\hline $\mathrm{S} 23$ & 3 & {$[-]$} & {$[-]$} & {$[-]$} & IDC & 5.36 & NR \\
\hline S27 & 3 & {$[+]$} & {$[+]$} & {$[-]$} & IDC & 2.62 & $\mathrm{R}$ \\
\hline S29 & NA & NA & NA & NA & IDC & 4.43 & NR \\
\hline S34 & 1 & {$[+]$} & {$[+]$} & {$[-]$} & invasive mucinous carcinoma of breast & 7.32 & NR \\
\hline S54 & 3 & {$[+]$} & {$[+]$} & {$[+]$} & IDC & 3.97 & NR \\
\hline S55 & 3 & {$[-]$} & {$[-]$} & {$[-]$} & IDC & 2.61 & $\mathrm{R}$ \\
\hline S87 & 3 & {$[-]$} & {$[-]$} & {$[-]$} & IDC & 0.00 & $\mathrm{R}$ \\
\hline S88 & 3 & {$[-]$} & {$[-]$} & {$[+]$} & IDC & 3.82 & $\mathrm{R}$ \\
\hline
\end{tabular}

ER: estrogene receptor; PR: progesterone receptor; HER2: ErbB2 receptor defined by immunohistochemistry; ATP-TCA: adenosine triphosphate tumor chemo-sensitivity assay; IDC: invasive ductal carcinoma; IDC-L: IDC with lobular features; NR: non responsive; R: responsive; NA not available. 


\section{DISCUSSION}

Chemotherapy resistance is one of the major obstacles to successful treatment of breast cancer [18]. Determination of clinical/pathological complete response to adjuvant chemotherapy takes time [19]. On the other hand, the use of in vitro methods such as ATP-TCA for the rapid determination of the response of cells to various agents, give the opportunity to find and/or validate biomarkers for predicting the response of tumors to chemo-therapeutics and this is an important part of precision medicine [20-22]. Culturing patient-derived tumor samples with chemo-therapeutic agents planned to be used for a patient and predicting the response rate via measuring ATP levels at the end of the culture period takes about a week. In this study, we showed that doxorubicin-resistant primary breast tumor samples have a higher twist expression. This finding supports the role of the twist transcription factor as a predictive biomarker of doxorubicin chemotherapy. As far as we know, there are no studies investigating the direct association of TWIST gene expression differences in primary breast tumors and their individual sensitivity to doxorubicin simultaneously.

The first evidence that TWIST overexpression was blocking the apoptosis had been reported in a study by Maestro et al. [23], which they performed on rhabdomyosarcomas. Subsequent studies indicating an association between TWIST gene expression and chemo-resistance are based on the cell lines. The blocking effect of TWIST upregulation on cytotoxicity has been further supported in a study performed on HtTA, HtTA-RelA, CCR3, PC3 cell lines. According to the evidences of this study, TWIST overexpression was controlling both necrotic and apoptotic pathways induced by cytotoxic agents. [24].

In cell line studies to investigate the drug resistance, increased concentrations of drugs are used to make cells resistant to the agents tested. This approach is due to the fact that chemo-therapeutic agents also promote resistant cell phenotypes. The first study indicating twist transcription factor as a biomarker performed with taxol resistant MCF-7 cell line, TWIST gene expression has been found to play important roles in drug resistance [25]. In a study conducted by Li et al. [26], based on the hypothesis that TWIST transcription factor can be effective in doxorubicin resistance, MCF7 cell lines were first rendered drug-resistant. Adriamycin-induced resistance was shown to be related to the more invasive potential and drug-resistant phenotype of the cells. This resistant phenotype was mediated by the epithelial-mesenchymal transformation process in which the twist transcription factor plays a major role [26]. Saxena et al. [27] reported that resistance to chemotherapy and twist transcription factor expression increased in invasive breast tumor cell lines exposed to doxorubicin. In accordance with this study, Li et al. [26] showed that TWIST1-mediated epithelial-mesenchymal transition was responsible for multiple drug resistance and twist depletion has enhanced the efficacy of doxorubicin by partial suppression of drug-induced P-glycoprotein expression in breast cancer cells. In our study, we found that twist transcription factor expression differed before tumor cells were exposed to any chemo-therapeutic agent, and there was a significant relationship between breast tumor response to doxorubicin and increased expression of the twist transcription factor. Therefore, in accordance with the other studies, the results of our study indicate that the expression of induced or naturally increased TWIST1 gene expression in breast tumors is associated with resistance to chemotherapy.

Having compatible results with earlier cell line studies on the role of twist overexpression as a biomarker for doxorubicin chemo-resistance, this study also supports effectivity of ATP-TCA assay method as a valuable tool for biomarker prediction and validation studies. However, drug-metabolizing reactions in the liver, tumor vascularization [28], hypoxia levels [29] are some of the factors that may affect the clinical drug response and may not be precisely reflected during the in vitro chemo-sensitivity assays. Together with these, the small sample number is the restrictive property of this study. In conclusion, the current study that has been performed with individual primary breast tumor samples supports earlier studies that have been performed with cell lines, suggesting the role of TWIST gene expression as a candidate biomarker for predicting the response of breast tumors to the chemotherapeutic agent doxorubicin.

Declaration of Interest. The authors report no conflicts of interest. The authors alone are responsible for the content and writing of this article.

\section{REFERENCES}

1. World Health Organization (https://www.who.int/ cancer/prevention/diagnosis-screening/breast-cancer/ en/).

2. Filipova A, Seifrtova M, Mokry J, Dvorak J, Rezacova M, Filip S, et al. Breast cancer and cancer stem cells: A mini-review. Tumori. 2014; 100(4): 363-369.

3. Dörfel S, Steffens CC, Meyer D, Tesch H, Kruggel L, Frank M, et al. Adjuvant chemotherapeutic treatment of 1650 patients with early breast cancer in routine care in Germany: Data from the prospective TMK cohort study. Breast Cancer. 2018; 25(3): 275-283. 
4. Ribeiro JT, Macedo LT, Curigliano G, Fumagalli L, Locatelli M, Dalton M, et al. Cytotoxic drugs for patients with breast cancer in the era of targeted treatment: Back to the future? Ann Oncol. 2012; 23(3): 547-555.

5. Duffy MJ, O’Donovan N, McDermott E, Crown J. Validated biomarkers: The key to precision treatment in patients with breast cancer. Breast. 2016; 29: 192201.

6. Online Mendelian Inheritance in Man, $\mathrm{OMIM}^{\circledR}$. McKusick-Nathans Institute of Genetic Medicine, Johns Hopkins University, Baltimore, MD, USA (https:// omim. org/).

7. Pajer P, Pecenka V, Karafiát V, Králová J, Horejsí $\mathrm{Z}$, Dvorák M. The twist gene is a common target of retroviral integration and transcriptional deregulation in experimental nephroblastoma. Oncogene. 2003; 22(5): 665-673.

8. Yin G, Chen R, Alvero AB, Fu HH, Holmberg J, Glackin $\mathrm{C}$, et al. TWISTing stemness, inflammation and proliferation of epithelial ovarian cancer cells through MIR199A2/214. Oncogene. 2010; 29(24): 3545-353.

9. Tseng JC, Chen HF, Wu KJ. A twist tale of cancer metastasis and tumor angiogenesis. Histol Histopathol. 2015; 30(11): 1283-1294.

10. Norozi F, Ahmadzadeh A, Shahjahani M, Sharabi S, Saki N. Twist as a new prognostic marker in hematological malignancies. Clin Transl Oncol. 2016; 18(2): 113-124.

11. Zhao Z, Rahman MA, Chen ZG, Shin DM. Multiple biological functions of Twist1 in various cancers. Oncotarget. 2017; 8(12): 20380-20393.

12. Qiao W, Jia Z, Liu H, Liu Q, Zhang T, Guo W, et al. Prognostic and clinicopathological value of Twist expression in breast cancer: A meta-analysis. PLoS One. 2017; 12(10): e0186191-e0186202.

13. Andreotti PE, Linder D, Hartmann DM, Cree IA, Pazzagli M, Bruckner HW. TCA-100 tumour chemosensitivity assay: Differences in sensitivity between cultured tumour cell lines and clinical studies. J Biolumin Chemilumin. 1994; 9(6): 373-378.

14. Cree IA, Kurbacher CM, Untch M, Sutherland LA, Hunter EM, Subedi AM, et al. Correlation of the clinical response to chemotherapy in breast cancer with ex vivo chemosensitivity. Anticancer Drugs. 1996; 7(6): 630-635.

15. Vogt U, Bielawski KP, Bosse U, Schlotter CM. Breast tumour growth inhibition in vitro through the combination of cyclophosphamide/metotrexate/5fluorouracil, epirubicin/cyclophosphamide, epirubicin/paclitaxel, and epirubicin/docetaxel with the bisphosphonates ibandronate and zoledronic acid. Oncol Rep. 2004; 12(5): 1109-1114.

16. Kurbacher CM, Cree IA. Chemosensitivity testing using microplate adenosine triphosphate-based luminescence measurements. Methods Mol Med. 2005; 110: 101-120.

17. Livak KJ, Schmittgen TD. Analysis of relative gene expression data using real-time quantitative PCR and the 2(-Delta Delta C(T)) Method. Methods. 2001; 25(4): 402-408.

18. Zelnak A. Overcoming taxane and anthracycline resistance. Breast J. 2010; 16(3): 309-312.

19. Hofmann D, Nitz U, Gluz O, Kates RE, Schin-koethe $\mathrm{T}$, Staib T, et al. WSG ADAPT - adjuvant dynamic marker-adjusted personalized therapy trial optimizing risk assessment and therapy response prediction in early breast cancer: Study protocol for a prospective, multi-center, controlled, non-blinded, randomized, investigator initiated phase II/III trial. Trials. 2013; 14: 261. doi: 10.1186/1745- 6215-14-261.

20. Ayyagari VN, Hsieh TJ, Diaz-Sylvester PL, Brard L. Evaluation of the cytotoxicity of the Bithionolcisplatin combination in a panel of human ovarian cancer cell lines. BMC Cancer. 2017; 17(1): 49.

21. Smith SC, Baras AS, Lee JK, Theodorescu D. The COXEN principle: Translating signatures of in vitro chemosensitivity into tools for clinical outcome prediction and drug discovery in cancer. Cancer Res. 2010; 70(5): 1753-1758.

22. Wang LF, Yin HT, Qian XP, Wei J, Zhao Y, Yu LX, et al. Beta-Tubulin III mRNA expression and docetaxel sensitivity in non-small cell lung cancer. Clin Invest Med. 2009; 32(6): E278-E284.

23. Maestro R, Dei Tos AP, Hamamori Y, Krasnokutsky $\mathrm{S}$, Sartorelli V, Kedes L, et al. Twist is a potential oncogene that inhibits apoptosis. Genes Dev. 1999; 13(17): 2207-2217.

24. Pham CG, Bubici C, Zazzeroni F, Knabb JR, Papa $\mathrm{S}$, Kuntzen C, et al. Upregulation of Twist-1 by NFkappaB blocks cytotoxicity induced by chemotherapeutic drugs. Mol Cell Biol. 2007; 27(11): 3920-3935.

25. Wang L, Tan RZ, Zhang ZX, Yin R, Zhang YL, Cui $\mathrm{WJ}$, et al. Association between Twist and multidrug resistance gene-associated proteins in Taxol $\AA$-resistantMCF-7 cells and a 293 cell model of Twist overexpression. Oncol Lett. 2018; 15(1): 1058-1066. 
26. Li QQ, Xu JD, Wang WJ, Cao XX, Chen Q, Tang F, et al. Twist1-mediated adriamycin-induced epithelialmesenchymal transition relates to multidrug resistance and invasive potential in breast cancer cells. Clin Cancer Res. 2009; 15(8): 2657-2665.

27. Saxena M, Stephens MA, Pathak H, Rangarajan A. Transcription factors that mediate epithelial-mesenchymal transition lead to multidrug resistance by upregulating ABC transporters. Cell Death Dis. 2011; 2: e179-e191.
28. Hillen F, Griffioen AW. Tumour vascularization: Sprouting angiogenesis and beyond. Cancer Metastasis Rev. 2007; 26(3-4): 489-502

29. Flamant L, Roegiers E, Pierre M, Hayez A, Sterpin $\mathrm{C}$, De Backer O, et al. TMEM45A is essential for hypoxia-induced chemoresistance in breast and liver cancer cells. BMC Cancer. 2012; 12: 391-407. 